\title{
The Development of Certification for Healthcare Interpreters in the United States
}

The International Journal for Translation \& Interpreting Research

trans-int.org

\author{
Mara Youdelman \\ Certification Commission for Healthcare Interpreters \\ Youdelman@healthcareinterpretercertification.org
}

DOI: ti.105201.2013.a06

\begin{abstract}
As the numbers of Limited English Proficiency (LEP) patients continue to grow, the demand for competent interpreting services increases. As these services become integrated into the delivery of culturally competent and patient-centered health care, the need to create formal systems for assessing the competence of interpreters to avoid medical harm, ensure effective communication, and provide truly patient-centered care is growing. Providers, healthcare administrators, coordinators of interpreting services and other interested parties are now realizing the significant benefits of working with trained and qualified interpreters. Further, providing effective language services is required by federal law for virtually all healthcare providers. Over twenty years of efforts have been building to develop a national certification program for healthcare interpreters. The Certification Commission for Healthcare Interpreters (CCHI) was formed to create a national, valid, credible and vendor-neutral certification program in the U.S. that honors the twenty-plus years of conversations and movement towards certification. The benefits of CCHI's national healthcare interpreter certification will extend to patients, interpreters, healthcare providers, healthcare administrators, coordinators of interpreting services, educators, and language services companies
\end{abstract}

Keywords: healthcare interpreter, medical interpreter, interpreter certification

\section{The Need for Competent Interpreters ${ }^{1}$}

A Spanish-speaking patient presented at the hospital and complained of dizziness, nausea, and vomiting. Her past medical history included kidney infection and chronic abdominal pain. Before the patient was treated, she went into cardiac arrest. As a result of untreated fluid in her brain, she suffered irreversible brain damage, became comatose, and lapsed into a vegetative state. The emergency room physician wrote in the medical record "Contact is the daughter, who speaks English and is translating tonight... by telephone." No competent interpreter was used at any point during the medical encounter and the patient's family alleged the patient did not receive adequate medical care prior to cardiac arrest. The hospital and five physicians paid over \$2 million in damages to the family (Quan, 2010).

${ }^{1}$ Special thanks to CCHI Commissioners Cathy Anderson, Natalya Mytareva, Elizabeth Nguyen and Karin Ruschke for their input and review. Also thanks to Georgia Patrick, The Communicators, and Cheryl Wild, Wild \& Associates, for their input. 
Unfortunately, this woman and her family are not alone in needing an interpreter to navigate the healthcare system or suffering the consequences from ineffective interpreting. In 2010, over 25 million individuals spoke English less than "very well", nearly $9 \%$ of the U.S. population (U.S. Census Bureau, 2010). Healthcare providers across the country are increasingly treating limited English proficient (LEP) patients:

- $80 \%$ of hospitals encounter LEP patients frequently: $63 \%$ encounter them daily or weekly, and $17 \%$ at least monthly (Hasnain-Wynia, Yonek, Pierce, Kang \& Greising, 2006).

- $81 \%$ of general internal physicians treat LEP patients frequently: $54 \%$ at least once a day or a few times a week, and $27 \%$ at least a few times per month (Ginsburg, 2007).

- $84 \%$ of Federally Qualified Health Centers provide clinical services daily to LEP patients: $45 \%$ see more than ten patients a day, and $39 \%$ see from one to ten LEP patients a day (National Association of Community Health Centers, 2008).

In addition to the high numbers of LEP patients treated by healthcare providers across the country, there is also growing recognition of the problems of using untrained and incompetent interpreters. According to a 2010 study analyzing the claims from one malpractice carrier, researchers found that $2.5 \%$ of the carrier's claims involved issues related to language. As in the example above, many of these cases resulted in patients suffering irreparable harm, and in some cases, death. In one case, a child was used to interpret before the child suffered respiratory arrest, and in another case, a patient incorrectly had a leg amputated. The same study noted that in 32 of 35 cases identified as involving language barriers, the healthcare providers did not use competent interpreters. In twelve cases, family members or friends were used as interpreters, including minor children (Quan, 2010).

Research documents that the lack of language services can both diminish the quality of health care and/or create significant barriers to care for limited English proficient individuals. (See Flores et al., 2003; Gandhi et al., 2000; Pitkin \& Baker, 2000. For an annotated bibliography see Jacobs, Agger-Gupta, Chen, Piotrowski \& Hardt, 2003). In one study, over $25 \%$ of LEP patients who needed an interpreter, but did not get one, reported they did not understand their medication instructions. In comparison, in the same study, only two percent of those who either did not need an interpreter or who needed and received one did not understand medication instructions (Andrulis, Goodman \& Pryor, 2002). Language barriers also impact access to care: non-English speaking patients are less likely to use primary and preventive care and public health services and are more likely to use emergency rooms. Once at the emergency room, they receive far fewer services than do English speaking patients (see, e.g., Bernstein et al., 2002; Watt, Howel \& Low, 1993; Fox \& Stein, 1991).

Further, the problems of using incompetent interpreters - particularly family members and friends, but also bilingual staff who have neither been assessed for their language proficiency nor trained as interpreters - have been well documented. The use of untrained family members and friends to interpret for non-English-speaking patients has been associated with omissions, additions, substitutions, volunteered opinions, and semantic errors that can result in serious distortions of the content of physician and patient exchanges (Baker, Parker, Williams, Coates \& Pitkin, 1996; Woloshin, Bickell, Schwartz, Gany \& Welch, 1995; see also Quan, 2010). One study noted that interpreting errors by "ad hoc" interpreters - including family 
members and friends - are significantly more likely to have potential clinical consequences than interpreting provided by hospital interpreters (Flores et al., 2003).

As demographic trends continue to evolve, the prevalence, composition and geographic distribution of languages spoken will continue to be fluid and necessitate the ongoing assessment of language needs for LEP patients. Multilingualism is spreading rapidly, in rural states and counties as well as urban environments. Between 1990 and 2000, 15 states experienced more than 100\% growth in their LEP populations: Arkansas, Colorado, Georgia, Idaho, Kansas, Kentucky, Minnesota, Nebraska, Nevada, North Carolina, Oregon, South Carolina, Tennessee, Utah, and Washington. We are likely to see similar developments with the results of the 2010 Census.

Further, providing effective language services is required by federal law for virtually all healthcare providers. In 1964, Congress passed Title VI of the Civil Rights Act. This is a civil rights law that prohibits discrimination. Its purpose is to ensure that federal money is not used to support healthcare providers who discriminate on the basis of race, color, or national origin. Title VI says:

No person in the United States shall, on ground of race, color, or national origin, be excluded from participation in, be denied the benefits of, or be subjected to discrimination under any program or activity receiving Federal financial assistance.

This law was reinforced by Executive Order 13166, which reiterated the requirements of Title VI in 2000. The federal Department of Health and Human Services (HHS) and the courts have applied this statute to protect national origin minorities who do not speak English well. In 2003, HHS issued specific guidance to its federal fund recipients outlining the expectations to provide language services in its "LEP Guidance." Thus, recipients of federal funding must take reasonable steps to ensure that people with LEP have meaningful access to their programs and services. Every state has at least some state-specific legislation regarding language access (Perkins \& Youdelman, 2008). In 2010, enactment of the Patient Protection and Affordable Care Act included an expanded nondiscrimination requirement.

As the numbers of LEP patients continue to grow, the demand for interpreting services increases. As these services become integrated into the delivery of culturally competent and patient-centered health care, the need to create formal systems for assessing the competence of interpreters to avoid medical harm, ensure effective communication, and provide truly patientcentered care is growing. Providers, healthcare administrators, coordinators of interpreting services and other interested parties are now realizing the significant benefits of working with trained and qualified interpreters. Some healthcare administrators have sought to establish or validate interpreter credentials through colleague references and referrals, as few universal, interpreter credentialing processes exist. However it is not clear that competence is actually being measured. Since this system of interpreter references and referrals can be unreliable and is certainly inconsistent, there has been growing recognition of the need to develop national standards for training and nationwide certification for healthcare interpreters. 


\section{The Move towards Healthcare Interpreter Certification}

For more than 20 years, efforts have been building to develop a national certification program for healthcare interpreters. As noted above, these efforts are in response to the increasing diversity of the country, greater focus on the legal requirements to provide competent language services, and a desire for national standards for interpreter competency.

Interpreters themselves have often been the catalyst for certification, beginning in the 1990s. In 1994, the Society of Medical Interpreters and the Cross Cultural Health Care Program, both based in Washington State, formed a "National Working Group" to examine healthcare interpreting. In 1995, Washington State began certifying interpreters who were interpreting for its Department of Social and Health Services. The initiation of this certification program arose from lawsuits challenging the state's provision of competent language services (Youdelman \& Perkins, 2002). In 1996, the California Healthcare Interpreting Association (CHIA) was born. In 1995, the Massachusetts Medical Interpreter Association (MMIA) published the first Standards of Practice for healthcare interpreters and, in 1997, held its first conference. Prior to the beginning of that conference, and with the support of the W.K. Kellogg Foundation, the National Working Group met to discuss, among other topics, its future. The group decided to become the National Council on Interpreting (originally "Interpretation") in Health Care (NCIHC). In 1998, NCIHC was officially launched. Over the past fifteen years, NCIHC has published a series of working papers examining issues related to healthcare interpreting, including the "Guide to Initial Assessment of Interpreter Qualifications” in 2001.

The move towards national certification also was based in various state efforts to improve the qualifications of healthcare interpreters. In 2001, Oregon passed legislation to develop qualification and certification of medical interpreters. In 2003, Indiana set up a commission to develop a certification process. North Carolina has been developing certification as a precursor to establishing payments for interpreters in Medicaid and its Children's Health Insurance Program. Texas recently enacted legislation to develop qualifications for healthcare interpreters and translators.

Providing stepping-stones to certification, MMIA, CHIA, and NCIHC have all undertaken work developing codes of ethics, standards of practice, or certification pilot programs. In 2002, CHIA published the California Standards for Healthcare Interpreters. In 2003, MMIA, CHIA, and NCIHC co-piloted a certification test for Spanish interpreters (See National Council on Interpreting in Health Care, 2003). In 2004, NCIHC published the National Code of Ethics for Interpreters in Healthcare and, in 2005, published the National Standards of Practice for Interpreters in Healthcare. In 2006, the California Endowment examined issues related to certification and published A Primer, a Status Report, and Considerations for National Certification.

Efforts at developing certification picked up steam after 2006. Throughout 2006 and 2007, NCIHC held twelve national forums on certification. In May of 2007 and 2008, Language Line Services, a for-profit vendor of language services, held the first two National Medical Interpreter Certification Forums in Boston, Massachusetts and Portland, Oregon. Then, in June 2007, the Interpreting Stakeholder Group (ISG) — a membership group within the Upper Midwest Translators and Interpreters Association - of Minnesota convened an Expert Panel on Community Interpreter Testing and Certification, to further ongoing national discussion of certification for healthcare interpreters. The three goals of the meeting were to: 
- convene a group of people with experience and expertise regarding assessment of interpreter qualifications;

- begin to assess what we know and what we need to do to build a fair and reliable certification process;

- explore how state and national initiatives can work together for their mutual benefit.

Representatives from NCIHC, CHIA and IMIA and other organizations attended the Expert Panel meeting. The recommendations from the meeting were to move forward with certification by identifying a national organizing or coordinating group to take the lead.

With the recommendations from this Expert Panel in hand, NCIHC secured funding from The California Endowment to advance national certification. NCIHC invited CHIA, IMIA and the American Translators Association (ATA) to form a steering committee for a new coalition, the National Coalition on Health Care Interpreter Certification (NCC). Through an open call for nominations, the NCC Steering Committee selected fourteen additional organizations to participate, representing the breadth of the interpreting and healthcare arenas. The purpose statement of the NCC was as follows:

The National Coalition on Healthcare Interpreter Certification (NCC) is committed to developing standards for a valid, credible, inclusive, and transparent national process to ensure competency of healthcare interpreters and improve access and quality of care for patients with limited English proficiency in our culturally diverse communities.

While the NCC provided much of the groundwork towards establishment of national certification, it was not organized as a legal entity and lacked many of the structures needed to develop certification. In 2009, seeking a more formal organizational and legal structure to develop certification, fifteen of the NCC's original members launched the Certification Commission for Healthcare Interpreters (CCHI). CCHI's mission is to create a national, valid, credible, and vendor-neutral certification program that honors the twenty-plus years of conversations and movement towards certification. CCHI is committed to providing a national set of industry-formed and approved standards, and an assurance of competency through an accredited, professional certification program. CCHI's founders felt strongly about involving a broader array of stakeholders and thus formed advisory panels to bring together many of the healthcare provider associations, policymakers, and experts in certification to advise CCHI. After its official launch in September 2009, CCHI initiated development of its certification program.

\section{Developing a Valid and Credible Certification Program}

CCHI committed to developing a valid and credible certification program, closely following national standards from the National Commission for Certifying Agencies (NCCA) and certification industry best practices. "Valid" means that the certification test measures what it intends to measure. It encompasses the idea of test use as well, i.e., the decisions made based on the test scores need to be consistent with the intended purpose of the test. For example, the Medical College Admission Test (MCAT) is a valid and reliable (i.e., repeatable and consistent across implementers and graders) test 
for admission to medical college, but it is not valid for admission to private high schools (Wild, n.d.). "Credible" means that those taking the examination as well as those using the examination as a measure of competency can rely on the certification entity as having followed the necessary steps to create a valid and reliable examination. It also reflects the ability of the organization to maintain its neutrality in creating a certification examination and the staying power of the organization because individuals want to ensure that the time and money invested in obtaining certification will result in a credential that outlasts the individual's professional life.

$\mathrm{CCHI}$ strives to follow specific steps to ensure that its certification program is valid and credible. First, CCHI adheres to NCCA's national standards for developing and maintaining a certification examination.

Second, CCHI appropriately involves healthcare interpreters, managers/supervisors of healthcare interpreters, other medical professionals, and consumer representatives (the stakeholders) in the development and communication about the certification program.

The steps involved in the development of $\mathrm{CCHI}$ certification program included:

- forming a Job/Task Analysis Committee;

- identifying the critical knowledge, skills and abilities required;

- conducting a national Job/Task Analysis Survey to define the profession as it exists today;

- analyzing the data and compiling a report from the Job/Task Analysis Survey;

- developing test specifications based on the Job/Task Analysis including identifying the content and weightings;

- developing the certification tests using subject matter experts;

- writing, reviewing, and approving test items;

- pilot testing the examinations;

- $\quad$ setting cut scores using subject matter experts and recognized psychometric principles; and

- evaluating all tests in the certification process using item and test analysis.

These steps are the minimum requirements for developing a valid test and are included in the CCHI Standards for Certification Programs.

To ensure validity, a certification body needs to make sure that the development of a certification program involves a wide range of certification stakeholders and that certification stakeholders contribute to the development of the examinations and the decisions about its use.

Clarence Chaffee, founding principal of the Caviart Group, discussed defining the profession without bias as follows:

As much as we would like to think otherwise, people come with biases, personal motives and prejudices, all of which are born out of our individual experiences... you have to create a process that reduces the impact of individual biases.... You do so by specifically involving representatives from the breadth of the profession and by including as many independent voices as possible. (Chaffee, n.d.)

With the intention of overcoming any bias or prejudice, CCHI took very deliberate steps to involve the interpreting profession. First, CCHI brought together Subject Matter Experts (SMEs) who represented the depth and 
breadth of the profession to develop its Job/Task Analysis Survey. CCHI went through an extensive selection process to develop a SME panel that truly represents a real cross section of the interpreting field. This involved first collecting information on the demographic makeup of the profession (including individual demographics such as gender, age, race, and education; career demographics such as years of experience, career path, language acquisition, and job title; and practice demographics such as employer type, community density, geographic location, practice setting, mode of interpreting, and languages interpreted). Next, $\mathrm{CCHI}$ identified a large number of potential panel members based on their demographic information and then selected a panel of ten that best represented the industry overall. The wide representation of the panel helps assure that the content of the Job/Task Analysis reflects all parts of the healthcare interpreting body of knowledgea very important prerequisite to assuring that the survey results will identify the appropriate content areas for the test and not leave out important areas (adapted from Wild, n.d.).

These SMEs developed a list of the tasks undertaken by healthcare interpreters as well as the knowledge, skills, and abilities (KSAs) needed to perform those tasks on the job at the present time. These tasks and KSAs were developed into a draft survey, which was pilot tested by a group of 35 individuals to ensure that all relevant tasks and KSAs were included. After finalizing the survey based on the comments received during the pilot, $\mathrm{CCHI}$ released the Job/Task survey nationally in January 2010. Nearly 2,500 individuals participated in the survey, representing over 140 languages, and thus contributed to defining the content of the certification test (Certification Commission for Healthcare Interpreters, 2010). According to psychometric experts, $\mathrm{CCHI}$ achieved well beyond the minimal requirements necessary for validity in conducting this survey (C. A. Wild \& C. Chaffee, personal communication). The results of the survey were analyzed and led to the adoption of CCHI's test "blueprint," the content outline of the test.

CCHI continued to involve experts from across the country as it moved into test development. CCHI undertook a second national recruitment and implemented a selection process to identify qualified item writers and item reviewers for participating in the development of its initial certification examination. Using the results from the national survey and its blueprint, these SMEs worked throughout the summer and fall of 2010 to write and review items for CCHI's examination.

The development of CCHI's first examination proceeded with the expert advice from consultants and professionals in the certification industry. The examination is comprised of two parts. The Associate Healthcare Interpreter ${ }^{\mathrm{TM}}\left(\mathrm{AHI}{ }^{\mathrm{TM}}\right)$ examination is a written English multiple-choice test, available to interpreters who interpret in all languages. The Certified Healthcare Interpreter ${ }^{\mathrm{TM}}\left(\mathrm{CHI}^{\mathrm{TM}}\right)$ examination is a bilingual oral performance (or skills-based) examination, initially developed to test Spanish interpreters and then for Arabic and Mandarin interpreters. The $\mathrm{CHI}^{\mathrm{TM}}$ examination is bidirectional, requiring candidates to interpret to/from English and to/from the non-English language. Pursuant to the results of CCHI's Job/Task Survey, the $\mathrm{CHI}^{\mathrm{TM}}$ tests consecutive interpreting, simultaneous interpreting, sight translation, and translation skills. To ensure compliance with CCHI standards and industry best practices, $\mathrm{CCHI}$ undertook specific tasks to develop the written examination, including:

- conducting an item development workshop with SMEs to write, review, and validate multiple-choice items; 
- undertaking psychometric, editorial, and linguistic review of the multiple-choice items;

- conducting an item review workshop with SMEs to make necessary revisions;

- pilot testing;

- conducting item analysis and summary statistics to verify examination keys;

- $\quad$ setting cut scores;

- equating multiple forms of the examination; and

- finalizing the examination for national distribution.

The specific tasks in development of the $\mathrm{CHI}^{\mathrm{TM}}$ oral examination are similar to the $\mathrm{AHI}^{\mathrm{TM}}$ written examination but include additional steps since it is an oral performance examination. Initially, the $\mathrm{CHI}^{\mathrm{TM}}$ examination was developed by a group of interpreters who work in many languages. Once the examination was developed, the oral prompts were transcreated (i.e., adapted to account for linguistic and culture differences) into Spanish. During subsequent examination development, the oral prompts were transcreated into Arabic and Mandarin. The steps used to create the Spanish examination were:

- conducting two development workshops with SME interpreters which included instruction on establishing the evaluation scales/scoring criteria and developing oral prompts and model responses;

- creation of oral prompts and model responses in English and their transcreation in Spanish;

- evaluation of scales/scoring criteria to review and validate the prompts and model responses;

- psychometric, editorial, and linguistic review of the oral exam prompts and model responses (both English and Spanish);

- conducting an item review workshop with SMEs to make necessary revisions;

- pilot testing;

- conducting statistical reliability analysis and inter-rater reliability;

- setting cut scores;

- conducting evaluator training to evaluate and consistently score model responses;

- equating multiple forms of the examination; and

- finalizing the examination for national distribution.

The same steps were used to develop the Arabic and Mandarin examinations with the exception of setting the evaluation scales/scoring criteria since these are the same for all three $\mathrm{CHI}^{\mathrm{TM}}$ examinations.

During the development workshops with SMEs, participants:

- wrote and reviewed multiple-choice questions or the prompts for the $\mathrm{CHI}^{\mathrm{TM}}$ examination;

- critiqued all items, prompts, and scenarios so that the writers experienced independent evaluation of their own items and prompts/scenarios and used that feedback to create the best test possible; and

- reviewed, classified, and validated each new item and prompt/scenario. 
$\mathrm{AHI}^{\mathrm{TM}}$ multiple-choice items must be judged, by consensus of the reviewers, to meet the following standards:

- mastery of the knowledge tested by the item is essential for competent practice;

- the knowledge tested by the item is either moderately important or of greatest importance to the assessment of competent practice;

- a correct response to the item would differentiate adequate from inadequate performance for the practitioner;

- the item has a verified reference;

- the item is appropriate for an entry-level healthcare interpreter;

- the keyed answer is correct;

- the keyed answer could be defended if necessary; and

- the distracters (e.g., incorrect answers) are incorrect, but plausible.

$\mathrm{CHI}^{\mathrm{TM}}$ performance test prompts are evaluated according to the following guidelines:

- the prompt leads the candidate to apply the skills necessary for the required response;

- sufficient information is available in the prompt for the candidate to provide the required response;

- all inconsistencies in the prompt have been rectified;

- the scoring criteria cover all the necessary skills to perform the technique or skill;

- the scoring criteria are in the proper sequence;

- each scoring criterion focuses the evaluator's attention on a different aspect of performance (i.e., scoring criteria are mutually exclusive);

- each scoring criterion asks the evaluator to assess a single aspect of performance;

- the evaluator will interpret the scoring criteria in the intended manner;

- the candidate's performance is not affected by his/her regional or educational background; and

- the scoring criteria are supported by published references.

Following the development meetings, psychometricians and linguistic consultants reviewed and edited the items/prompts/scenarios to ensure that they were psychometrically sound, grammatically correct, and adhered to appropriate sociolinguistic conventions. The review for $\mathrm{AHI}^{\mathrm{TM}}$ multiplechoice items encompassed the following criteria:

- the item's stem (the main point of the question) presents a definite problem;

- the item's stem is free of irrelevant material;

- negatively stated stems are used only when necessary;

- all response options are grammatically consistent with the stem;

- the item has only one correct or clearly best answer;

- all distractors are plausible;

- the distractors are drawn from the same category/pool as the correct response;

- the distractors are similar in length, complexity, vocabulary, and grammatical construction as the correct response; 
- the item is free of cultural bias;

- "all of the above" and "none of the above" are not used; and

- the terms "always" and "never" are not used, or used judiciously.

Following the psychometric, editorial, and linguistic review, the item or prompt was prepared for review and validation by item reviewers. Each item or prompt underwent independent reviews/validations by SMEs recruited as item reviewers. During the review process, SMEs evaluated each item's or prompt's importance, criticality, and relevance to the certified healthcare interpreter. Then SMEs reviewed the draft forms of the examinations. Following the assembly meetings, the selected items/prompts/scenarios were formatted in examination format, and final psychometric and editorial review of the examinations was conducted. Following this review, the appropriate sections of the oral examinations were formatted for pilot testing.

Individuals who pass the $\mathrm{AHI}^{\mathrm{TM}}$ examination and for whom a $\mathrm{CHI}{ }^{\mathrm{TM}}$ examination is not available in their language earn the credential of "Associate Healthcare Interpreter" (AHI ${ }^{\mathrm{TM}}$ ). This credential, however, does not certify the individual's actual competency to interpret, only that the individual has demonstrated competency in knowledge of the subject matters tested on the examination. The AHI ${ }^{\mathrm{TM}}$ credential verifies the individual's intent and readiness to obtain certification. Individuals who pass both the $\mathrm{AHI}^{\mathrm{TM}}$ and $\mathrm{CHI}^{\mathrm{TM}}$ examinations achieve professional certification and the title of "Certified Healthcare Interpreter" (CHI $\left.{ }^{\mathrm{TM}}\right)$ certificant. The difference between the $\mathrm{AHI}^{\mathrm{TM}}$ and $\mathrm{CHI}^{\mathrm{TM}}$ credentials is that a $\mathrm{CHI}$ is tested on the full range of tasks and KSAs identified by the Job/Task Analysis Survey and thus represents full certification. CCHI plans include developing the $\mathrm{CHI}^{\mathrm{TM}}$ examination in multiple languages and, for interpreters of languages of lesser diffusion, offering alternative paths to assess an individual's interpreting competency.

\section{Conclusion: The Benefits of Certification}

$\mathrm{CCHI}$ was the first healthcare interpreter certification program to receive accreditation by the National Commission for Certifying Agencies, the entity charged with accrediting certification programs. The benefits of CCHI's national healthcare interpreter certification extend to patients, interpreters, healthcare providers, healthcare administrators, coordinators of interpreting services, educators, and language services companies.

CCHI's certification ensures that interpreters possess specific demonstrable skills to establish effective communication between patients and healthcare providers. With certified competent interpreters, patients will be able to focus on their healthcare concerns rather than communication concerns. As for healthcare providers, ensuring competent interpreters helps to ensure accurate diagnosis and treatment, obtain informed consent, and prevent medical errors through effective communication.

For interpreters, certification is a means of separating competent interpreters from the larger candidate pool of less qualified interpreters. A valid and independent professional certification must first be recognized and adopted as the preferred choice by healthcare providers requesting interpreting services. This demand for professional qualifications will then incentivize healthcare interpreters to undertake the necessary training and career development to achieve the certification, creating an enhanced professional career path and lifelong advancement opportunities. 
For healthcare administrators, coordinators of interpreting services and other interested parties the significant benefits of working with trained and qualified interpreters include a positive impact on risk management, better cost controls, and higher patient compliance and satisfaction.

Certification offers a valid and credible way to measure competency and ensure compliance with legal and regulatory guidance on language access and the provision of "qualified" interpreters, as well as many state laws banning the use of children as interpreters.

A national certification also significantly benefits language services providers dedicated to investing in comprehensive professional training and development as an indicator of quality services, especially when healthcare providers begin expressing a preference for certified interpreters.

It takes a cohesive community of many people, all committed to the same values and vision of providing high quality healthcare to all individuals regardless of the language spoken by the patient, to play the many roles necessary to create and sustain a certification program. CCHI was formed as an independent certification organization to ensure that the values and vision respect the history of the profession. That is why the work to build the community of certification candidates, advisors, sponsors, healthcare organizations and others concentrating on patient care is as important as creating the certification programs, including exams, preparation, continuing education and recertification. And that is why CCHI developed its certification program with the involvement of thousands in the healthcare interpreting profession and other stakeholders. To prevent patients from an inability to participate in healthcare decisions because of language barriers or from suffering serious harm, CCHI offers its certification program as one concrete way to ensure the competency of those providing language services so that a patient can worry about getting better and not about being misunderstood. 


\section{References}

Andrulis, D. P., Goodman, N., \& Pryor, C. (2002). What a difference an interpreter can make: Health care experiences of uninsured with limited English proficiency. Boston, MA: The Access Project. Retrieved from http://accessproject.org/adobe/what_a_difference_an_interpreter_can make.pdf.

Baker, D. W., Parker, R. M., Williams, M. V., Coates, W. C., \& Pitkin, K. (1996). Use and effectiveness of interpreters in an emergency department. Journal of the American Medical Association, 275(10), 783-88.

Bernstein, J., Bernstein, E., Dave, A., Hardt, E., James, T, Linden, J., . . . Safi, C. (2002). Trained medical interpreters in the emergency department: Effects on services, subsequent charges, and follow-up. Journal of Immigrant Health 4(4), 171-76.

Certification Commission for Healthcare Interpreters. (2010). Job task analysis study and results. Retrieved from http://healthcareinterpretercertification.org/images/webinars/cchi\%20 jta\%20report-public.pdf.

Chaffee, C. (n.d.). Cultivating Certification. Certification Commission for Healthcare Interpreters. Retrieved from http://healthcareinterpretercertification.org/index.php?option=com_c ontent $\&$ view $=$ article\&id=104\&Itemid $=37$.

Flores, G., Laws, M. B., Mayo, S. J., Zuckerman, B., Abreu, M., Medina, L., \& Hardt, E. J. (2003). Errors in medical interpretation and their potential clinical consequences in pediatric encounters. Pediatrics, 111(1), 6-14.

Fox, S. A., \& Stein, J. A. (1991). The effect of physician-patient communication on mammography utilization by different ethnic groups. Medical Care, 29(11), 1065-82.

Gandhi, T. K., Burstin, H. R., Cook, E. F., Puopolo, A. L., Haas, J. S., Brennan, T. A., \& Bates, D. W. (2000). Drug complications in outpatients. Journal of General Internal Medicine, 15, 149-54.

Ginsburg, J. A. (2007). Language services for patients with limited English proficiency: Results of a national survey of internal medicine physicians. Washington, DC: American College of Physicians.

Hasnain-Wynia, R., Yonek, J., Pierce, D., Kang, R., \& Greising, C. H. (2006). Hospital language services for patients with limited English proficiency: Results from a national survey. Washington, DC: National Health Law Program and Health Research and Educational Trust.

Jacobs, E. A., Agger-Gupta, N., Chen, A. H., Piotrowski, A., \& Hardt, E. J. (2003). Language barriers in health care settings: An annotated bibliography of the research literature. Woodland Hills, CA: The California Endowment. Retrieved from http://www.calendow.org/uploadedFiles/language_barriers_health_ca re.pdf.

National Association of Community Health Centers. (2008). Serving patients with limited English proficiency: Results of a community health center survey. Retrieved from http://healthlaw.org/images/pubs/nhelp_lep-state-law-chart_12-2807.pdf. 
National Council on Interpreting in Health Care. (2003). Final report on the pilot of a certification process for Spanish-English interpreters in health care. Retrieved from

http://data.memberclicks.com/site/ncihc/NCIHC Certification Pilot Final_Report.pdf.

Perkins, J., \& Youdelman, M. (2008). Summary of state law requirements addressing language needs in health care. Washington, DC: National Health Law Program. Retrieved from http://healthlaw.org/images/pubs/nhelp_lep-state-law-chart_12-2807.pdf.

Pitkin, D. K., \& Baker, D. W. (2000). Limited English proficiency and Latinos' use of physician services. Medical Care Research and Review 57(1), 76-91.

Quan, K. (2010). The high costs of language barriers in medical malpractice. Washington, DC: National Health Law Program.

U.S. Census Bureau. (2010). Language spoken at home: 2010 American community survey 1-year estimates. Retrieved from http://factfinder2.census.gov/faces/tableservices/jsf/pages/productvie w.xhtml?pid=ACS 10 1YR S1601\&prodType=table

Watt, I. S., Howel, D., \& Low, L. (1993). The health care experience and health behavior of the Chinese: A survey based in Hull. Journal of Public Health 15(2), 129-36.

Wild, C. A. (n.d.). Report from the front lines. Certification Commission for Healthcare Interpreters. Retrieved from http://healthcareinterpretercertification.org/index.php?option=com_c ontent \&view $=$ article \&id $=123 \&$ Itemid $=37$

Woloshin, S., Bickell, N. A., Schwartz, L. M., Gany F., \& Welch, H. G. (1995). Language barriers in medicine in the United States. Journal of the American Medical Association, 273(9), 724-28.

Youdelman, M., \& Perkins, J. (2002). Providing language interpretation services in health care settings: Examples from the field. New York: Commonwealth Fund. Retrieved from http://www.commonwealthfund.org/ /media/Files/Publications/Fund \%20Report/2002/May/Providing\%20Language\%20Interpretation\%2 0Services\%20in\%20Health\%20Care\%20Settings\%20\%20Examples $\% 20$ from $\% 20$ the $\% 20$ Field/youdelman_languageinterp_541\%20pdf.p $\underline{\mathrm{df}}$ 